\title{
Impact of key pinch strength on patient preference for inflatable penile prosthesis: a prospective study comparing Coloplast ${ }^{\mathrm{TM}}$ and AMS $^{\text {TM }}$ models
}

\author{
John M. Masterson ${ }^{1} \cdot$ Laura Horodyski $^{1} \cdot$ Ronak Patel $^{1} \cdot$ Omer Kineish ${ }^{1} \cdot$ Taylor P. Kohn $^{2} \cdot$ Ranjith Ramasamy $^{1}$
}

Received: 5 January 2019 / Revised: 31 January 2019 / Accepted: 13 February 2019 / Published online: 4 March 2019

(C) Springer Nature Limited 2019

\begin{abstract}
Our purpose was to determine if key pinch strength is predictive of patient preference for a single IPP model among three currently available models (Coloplast ${ }^{\mathrm{TM}}$ Titan, Coloplast ${ }^{\mathrm{TM}}$ Titan Touch, and the Boston Scientific AMS $700^{\mathrm{TM}}$ ). We prospectively recruited men without penile prostheses over 65 years old from our urology clinic. Demographic and medical history were recorded. To measure key pinch strength study participants squeezed a dynamometer between their thumb and index finger while seated with their arm resting at $90^{\circ}$; the strongest of three attempts was recorded. Participants were asked to operate three inflatable penile prosthesis devices installed within identical penis models. The number of pumps required to achieve erection with each device was recorded. Participants were asked to rate difficulty of inflation on a 1-5 scale. Participants ranked, from best to worst, which device they preferred based on ease of inflation. A total of 100 men completed the study. Median age and key pinch strength were 70.0 years and 19.0 pounds. Coloplast Titan was the most favored pump based on ease of inflation (58\%). The median age, median key pinch strength, and median number of pumps required for erection were similar among men that favored Coloplast Titan as compared with AMS 700 and Coloplast Titan Touch. Multivariate linear regression of the 1-5 rating scale revealed lower grip strength to be associated with increased difficulty of inflation of Coloplast Titan Touch $(p=0.045)$. No other factors were associated with increased difficulty of inflation. Men with below-average key pinch strength may benefit from being offered a model other than Coloplast Titan Touch. Whether these findings translate to men who have already received implants remains to be determined. Nevertheless, evaluation of pinch strength should be considered in men prior to implantation of IPP.
\end{abstract}

\section{Introduction}

Erectile dysfunction (ED) is a relatively common disorder, with an estimated $20-40 \%$ of men aged $60-69$ years affected, increasing to $50-100 \%$ of men over age 70 years [1]. Traditionally, oral phosphodiesterase-5 inhibitors were considered first-line treatment, although they are not effective for all patients [2]. Second-line treatment included intracavernosal injections, urethral suppositories, and vacuum erection devices; however, discontinuation of these

John M. Masterson

Jmm557@med.miami.edu

1 Department of Urology, University of Miami Miller School of Medicine, Miami, FL, USA

2 Department of Urology, Johns Hopkins University, Baltimore, MD, USA modalities is high [2, 3]. Penile prosthesis, a surgical intervention, had been reserved as a third-line treatment modality [2]. However, in a 2018 guideline update, the American Urological Association now endorses a shared decisionmaking model for the treatment of ED, allowing penile prosthesis to become a first-line treatment in appropriate patients [2]. As a result, many will become candidates for penile prosthesis, contributing to the estimated 25,000 penile prostheses implanted annually in the United States [4, 5].

Overall satisfaction rates for inflatable penile prostheses (IPPs) are estimated at over $80 \%$ [6, 7]. Issues that may arise from IPPs include mechanical problems (pump failure, reservoir, or cylinder leakage) or non-mechanical issues (infection, erosion, and difficulty cycling pump) [7, 8]. Careful patient selection, such as exclusion of those who have progressive neurologic diseases or patients who do not have an able and willing partner to inflate the device for them, can help reduce rates of dissatisfaction secondary to difficulty of use. However, even with screening, occasionally patients are 


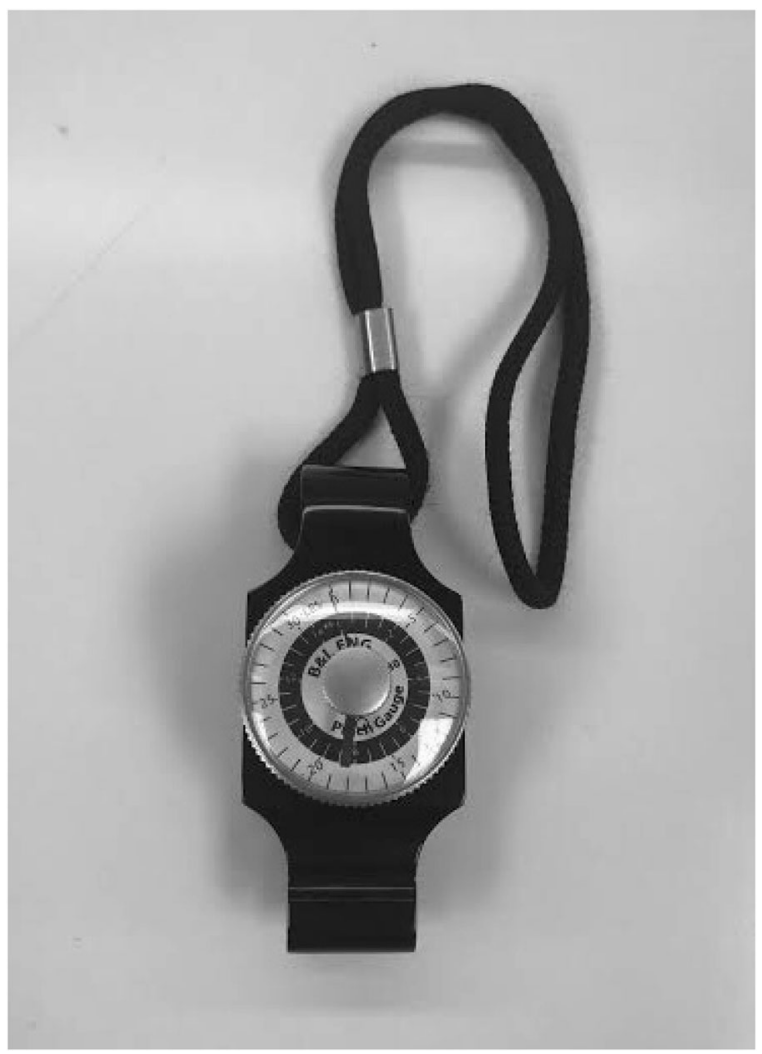

Fig. 1 Dynamometer

unable to successfully manipulate the prosthesis. If preoperative screening could indicate which patients are at risk for inability to manipulate the prosthesis, these patients could potentially be spared an expensive and invasive surgery that does not remedy their ED.

One potentially useful pre-operative screening tool is the evaluation of key pinch strength; the strength measured between the first and second digits [9]. A similar concept, hand grip strength, has been hypothesized to be a useful assessment of pre-operative frailty in patients undergoing IPP implantation, and has revealed that many patients undergoing IPP are indeed frail based on this metric, which may result in a longer post-operative recovery course and decreased device satisfaction [10]. Key pinch strength, however, is more precisely representative of the motion required to operate an IPP and may be a useful pre-operative predictor of device satisfaction. It is not currently known whether key pinch strength over a certain threshold is needed to easily operate IPP pumps, or if specific IPP models are easier to manipulate with decreased key pinch strength.

\section{Methods}

Following Institutional Review Board approval, men over 65 years of age were prospectively recruited from our

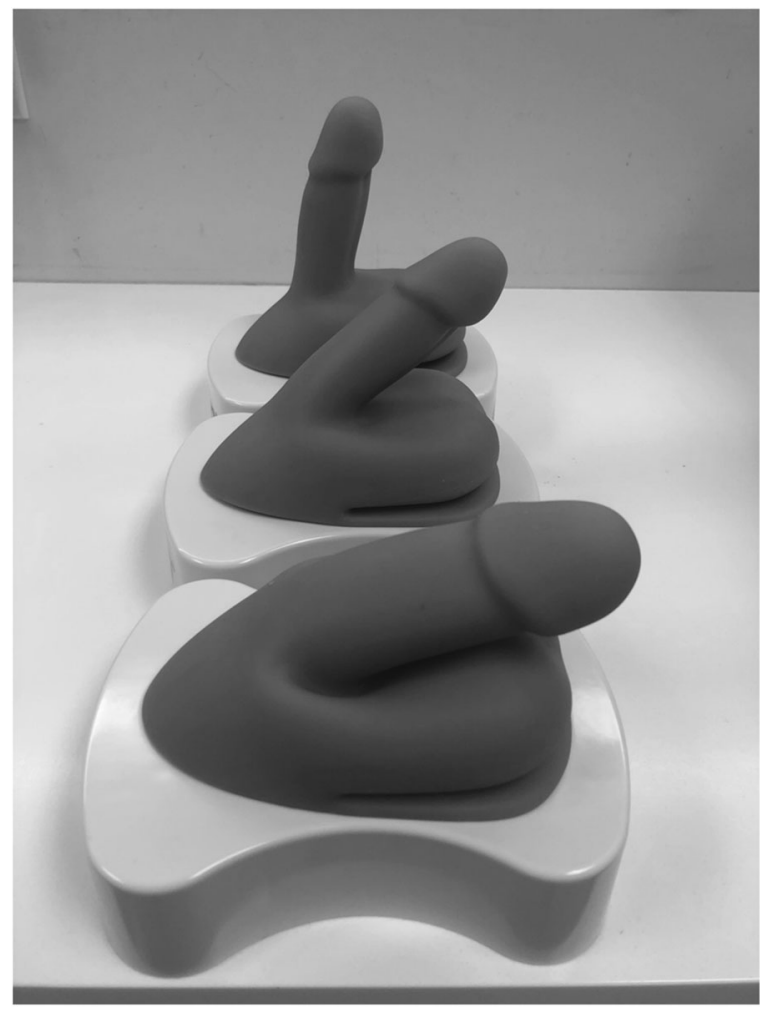

Fig. 2 The three inflatable penile prosthesis (IPP) devices housed within identical rubber penis models provided by Coloplast

outpatient urology clinic. Men were approached following their regularly scheduled clinic visit to participate in our study. Men who had already received a penile prosthesis were excluded, as well as men with neurological conditions affecting their manual strength and dexterity. Demographics and selected medical history were recorded, including age; right- versus left-hand dominance; history of hypertension, diabetes, cerebrovascular accident, coronary artery disease, peripheral artery disease, arthritis, carpal tunnel, or hand surgeries. To measure their key pinch strength, study participants were asked to squeeze a dynamometer between their thumb and index finger while seated with their arm resting at $90^{\circ}$ (Fig. 1). The strongest of three attempts was recorded. Participants were then asked to operate three separate IPP devices (Coloplast Titan, Coloplast Titan Touch, and AMS 700) installed within identical rubber penis models provided by Coloplast (Fig. 2). The number of full pumps of the device required to achieve erection with each device was recorded. Following inflation of each device, participants were asked to rate the difficulty of inflation on a scale of $1-5,1$ being not difficult at all to 5 being very difficult. Participants were then asked to rank, from best to worst, which device they preferred based on ease of inflation. We did not assess device deflation in this study. The order in which the models were presented to participants was randomized. 
Table 1 The mean reported difficulty of inflation score for each device increased with age for each pump model

\begin{tabular}{lllll}
\hline & \multicolumn{2}{l}{ Age } & & \\
\cline { 2 - 4 } & $65-70$ & $70-75$ & $75+$ & $p$-Value \\
\hline$N$ & 47 & 32 & 21 & \\
Strength & 20.36 & 18.66 & 18.86 & 0.17 \\
Titan score & $2.1 \pm 1.2$ & $2.1 \pm 0.8$ & $2.3 \pm 1.1$ & 0.425 \\
Titan Touch score & $2.7 \pm 1.2$ & $3.0 \pm 1.2$ & $3.4 \pm 0.7$ & $\mathbf{0 . 0 3 2 3}$ \\
AMS score & $2.3 \pm 1.2$ & $2.6 \pm 1.1$ & $2.9 \pm 1.4$ & $\mathbf{0 . 0 3 9 7}$ \\
\hline
\end{tabular}

This trend was significant for the Titan Touch and AMS 700 models. Significant values are bolded

Normality of data was tested using the Q-Q test. Multivariate linear regression at the $95 \%$ confidence interval was utilized to identify predictors of pump preference. All statistical analyses were conducted using STATA MP v15 (Stata-Corp, College Station, TX).

\section{Results}

A total of 100 men with a median age of 70.0 (range 65-87) years met inclusion criteria and were prospectively recruited to our study. Median key pinch strength for the population was 19 (range 10-28) pounds. The Coloplast Titan was most the most preferred pump by $58 \%$ of men, followed by the AMS 700 (29\%) and the Coloplast Titan Touch (13\%). The median age in years $(70.0,69.0$, and 73.0) and mean key pinch strength in pounds (19.6, 19.7, and 19.1 pounds) were similar among men who favored the Coloplast Titan as compared with those who AMS 700 and Coloplast Titan Touch pump. The median number of pumps required to achieve erection (5.0, 5.0, and 6.0) was also similar across the Coloplast Titan, AMS 700, and Coloplast Titan Touch models. Multivariate linear regression of the difficulty of inflation rating scale demonstrated that the men with lower pinch strength reported increased difficulty of inflation only for the Coloplast Titan Touch model $(p=0.045)$. When the study population was divided into age groups (65-70, $70-75,75+)$, the mean reported difficulty of inflation score increased with age for the Coloplast Titan Touch, as well as the AMS 700. No other factors were significantly associated with increased difficulty of inflation (Table 1, Fig. 3).

\section{Discussion}

In this study, we performed a prospective, head-to-head comparison of the currently available IPP models based on

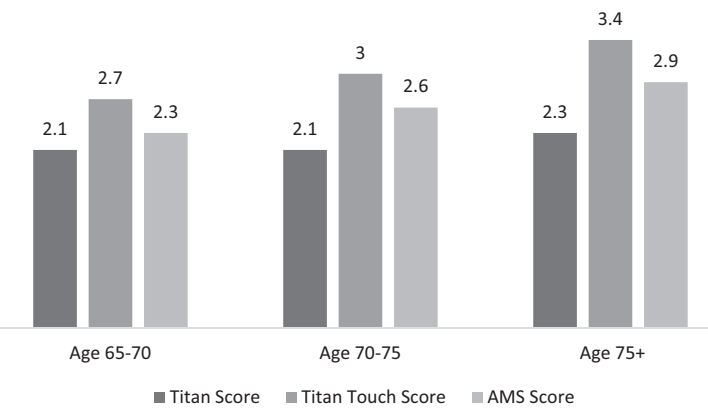

Fig. 3 The mean reported difficulty of inflation score for each device increased with age for each pump model

pump function to determine which was most preferred. We found the Coloplast Titan to be the overall most preferred IPP model based on ease of inflation. We found lower grip strength to be associated with increased reported difficulty of inflation of the Coloplast Titan Touch model. To our knowledge, this is the first study to perform a direct head-tohead comparison of the pump function of currently available IPP models. Our study contributes to a growing body of literature aimed toward identifying pre-operative clinical factors that can predict successful outcomes following IPP implantation.

The mean key pinch strength for our study population was 19 (range 10-28) pounds, whereas the median age of the population was 70.0 (range 65-87) years. This finding is supported by a 1985 study by Mathiowetz et al., which published normative data for several types of grip strength for adults. The authors reported that mean key pinch strength for this age group in the male population is 19.3 (SD 2.4) [9]. This comparison is significant, in that our study population consists entirely of men presenting to a urology clinic and may not accurately represent the agematched general population. However, this comparison confirms that our population has a similar mean key pinch strength to the general population.

The Coloplast Titan pump was the most preferred IPP pump overall, being ranked as best of the three options by more than half of men. The AMS 700 was rated as best by roughly one-third of men while the remainder preferred the Coloplast Titan Touch. Objective measurements of key pinch strength and number of pumps required to achieve device inflation did not vary significantly between men who ranked different devices as best, suggesting that these factors are unlikely to predict preference for any one model over the others. However, among men with lower key grip strength, patient-reported difficulty of inflation (rated 1-5) increased for the Coloplast Titan Touch model. This increased difficulty of inflation may at least partly explain why the Coloplast Titan Touch was rated as best only $13 \%$ of the time, fewest of the three models. The additional finding that 
reported difficulty of inflation increased with participant age for the Coloplast Titan Touch and AMS 700 models suggests that older men may not be able to operate these pumps, as well as younger recipients and require evaluation of preoperative key pinch strength.

There is a growing body of literature directed toward finding predictors of patient satisfaction with IPP and matching specific patients with the best available model for them. Factors assessed include the intrinsic properties of IPP models such as cylinder girth, axial rigidity, and impact of device add-ons like rear-tip-extenders, among others $[11,12]$. Less studied is the role that key pinch strength plays in patient satisfaction with IPP. In a 2016 pilot study, Brennan et al. discussed the importance of assessing patient frailty prior to IPP surgery in order to achieve better surgical outcomes [10]. The authors advocate for the use of hand grip strength as an especially logical assessment of patient frailty prior to IPP given the hand strength and dexterity required to operate an implant. They report that the majority of their IPP patients (77\%) are indeed frail using a hand grip strength cut off of 70 pounds, and that frail patients required additional post-operative for learning device manipulation than their non-frail counterparts [10]. However, the authors do not report on patient satisfaction following IPP, as it is outside the scope of their study, which focused mainly on hand grip strength as a measure of patient fitness for surgery, not fitness for IPP.

Strengths of our study include strict inclusion criteria and the randomized order in which study participants tested each IPP model. There was an obvious learning curve to using the IPP models and randomization was able to effectively control for this potential bias. Penile implant utilization is increasing in the over 65 years old population and thus our study captures the demographic most likely to receive an IPP [13]. Limitations include small sample size, lack of a validated questionnaire to assess for patient satisfaction related to ease of inflation of IPP, and inability to translate these results to in vivo IPPs. Limitations also include our inability to assess other means of pump inflation, such as utilizing the thenar eminence and multiple fingers to inflate the pump, which is more similar to hand grip strength.

\section{Conclusions}

Key pinch strength is a useful assessment in men prior to implantation of IPP. Men with low key pinch strength may benefit from being offered a model other than Coloplast Titan Touch. Whether these findings translate to men who will receive an IPP remains to be determined.

\section{Compliance with ethical standards}

Conflict of interest The authors declare that they have no conflict of interest.

Publisher's note: Springer Nature remains neutral with regard to jurisdictional claims in published maps and institutional affiliations.

\section{References}

1. Shamloul R, Ghanem H. Erectile dysfunction. Lancet. 2013;381:153-65. https://doi.org/10.1016/S0140-6736(12)60520-0.

2. Burnett AL, Nehra A, Breau RH, Daniel J, Faraday MM, Hakim LS, et al. Erectile dysfunction: AUA guideline. 2018;1-90. https:// doi.org/10.1037//0096-1523.10.4.573.

3. Sung HH, Ahn JS, Kim JJ, Choo SH, Han DH, Lee SW. The role of intracavernosal injection therapy and the reasons of withdrawal from therapy in patients with erectile dysfunction in the era of PDE5 inhibitors. Andrology. 2014;2:45-50. https://doi.org/10. 1111/j.2047-2927.2013.00155.x.

4. Carson CC. Diagnosis, treatment and prevention of penile prosthesis infection. Int J Impot Res. 2003;15:S139-S146. https://doi. org/10.1038/sj.ijir.3901091.

5. Darouiche RO, Bella AJ, Boone TB, Brock G, Broderick GA, Burnett AL, et al. North American consensus document on infection of penile prostheses. Urology. 2013;82:937-42. https:// doi.org/10.1016/j.urology.2013.05.048.

6. Rajpurkar A, Dhabuwala CB. Comparison of satisfaction rates and erectile function in patients treated with Sildenafil, intracavernous prostaglandin E1 and penile implant surgery for erectile dysfunction in urology practice. J Urol. 2003;170:159-63. https://doi. org/10.1097/01.JU.0000072524.82345.6D.

7. Ji YS, Ko YH, Song PH, Moon KH. Long-term survival and patient satisfaction with inflatable penile prosthesis for the treatment of erectile dysfunction. Korean J Urol. 2015;56:461 https:// doi.org/10.4111/kju.2015.56.6.461.

8. Montorsi F, Rigatti P, Carmignani G, Corbu C, Campo B, Ordesi G, et al. AMS three-piece inflatable implants for erectile dysfunction: a long-term multi-institutional study in 200 consecutive patients. Eur Urol. 2000;37:50-55. https://doi.org/10.1159/000020099.

9. Mathiowetz V, Kashman N, Volland G, Weber K, Dowe M, Rogers S. Grip and pinch strength: normative data for adults. Arch Phys Med Rehabil. 1985;66:69-74. http://www.ncbi.nlm.nih.gov/ pubmed/3970660. Accessed 28 Jan 2019.

10. Brennan MS, Barlotta RM, Simhan J. Frailty assessments in surgical practice: what is frailty and how can it be used in prosthetic health? Sex Med Rev. 2018;6:302-9. https://doi.org/10. 1016/j.sxmr.2017.06.006.

11. Pastuszak AW, Lentz AC, Farooq A, Jones L, Bella AJ. Technological improvements in three-piece inflatable penile prosthesis design over the past 40 years. J Sex Med. 2015;12:415-21. https:// doi.org/10.1111/jsm.13004.

12. Wallen JJ, Barrera EV, Ge L, Pastuszak AW, Carrion RE, Perito $\mathrm{PE}$, et al. Biomechanical comparison of inflatable penile implants: a cadaveric pilot study. J Sex Med. 2018;15:1034-40. https://doi. org/10.1016/j.jsxm.2018.05.014.

13. Lee DJ, Najari BB, Davison WL, Al Awamlh BAH, Zhao F, Paduch DA, et al. Trends in the utilization of penile prostheses in the treatment of erectile dysfunction in the United States. J Sex Med. 2015;12:1638-45. https://doi.org/10.1111/jsm.12921. 